\title{
Darnton, Robert Edición y subversión - Literatura clandestina en el antiguo régimen. México: Turner \&Fce, 2003
}

\author{
JAVIER BONILLA SAUS, UNIVERSIDAD ORT URUGUAY
}

Fecha de recepción: junio de 2014

Fecha de aceptación: agosto de 2014

I.- A finales de 2013, por razones ajenas a esta reseña, intenté rastrear por qué vías de comunicación Leviatán, y en general la obra de Hobbes, había llegado a hacerse realmente familiar para los autores de la Ilustración francesa. La bibliografía sobre el tema no era abundante por lo que busqué, inicialmente sin éxito, cuándo y cómo se había conocido en Francia la traducción de la obra. Un siglo antes, Hobbes había tenido relaciones fluidas con Mersenne, Gassendi, Galileo, y hasta con Descartes, pero muchos textos del siglo XVII estaban en latín y, aunque las relaciones de Hobbes con el continente fueron intensas, también fueron tempranas y generalmente anteriores a la publicación del grueso de su obra significativa.

Una búsqueda en BNF-Gallica me deparó una sorpresa. El primertraductor al francés del Ce Cive, De Corpore y De Homine resultaba ser el mismísimo Baron d'Holbach ${ }^{1}$. La lectura del facsimilar de la traducción original reveló que la edición era de 1787, el traductor mencionado en portada era “...un ami...” y la editorial de esa primera versión de Hobbes en francés era "La Société Typographique de Neuchâtel".

Este hallazgo me recordó antiguas lecturas de Robert Darnton y logré, en pocos días, conseguir un ejemplar del libro que reseñamos. Su lectura me reafirmó que algunas de las características de la edición de la inmensa literatura clandestina del siglo XVIII, estudiada por Darnton, estaban allí presentes en la traducción de Holbach: el nombre del traductor se disimulaba en la edición, la fecha de ésta era problemática y, sobretodo, el sello editorial de los dos to-

1 http://gallica.bnf.fr/ark:/12148/bpt6k6132274w.r=Le+Citoyen+de+Hobbes+Traduction+du+Baron+d\%C2\%B 4Holbach.langES http://gallica.bnf.fr/ark:/12148/bpt6k5859181w.r=Le+Citoyen+de+Hobbes+Traduction+du +Baron+d\%C2\%B4Holbach.langES (Consulta del 28/05/14) 
mos ubicados era el de la mencionada editorial suiza, especializada en publicar enormes cantidades de la literatura prohibida en Francia en el período, que fue la fuente fundamental del trabajo académico de Darnton, sobre la "baja literatura" a finales del Antiguo Régimen.

Muchos textos de Darnton son de las últimas décadas del siglo pasado2 pero solo estuvieron disponibles en inglés y francés. Mucho más tardíamente, llegó su traducción al castellano. Hoy están disponibles: La gran matanza de gatos y otros episodios en la historia de la cultura francesa (1999), El coloquio de los lectores. Ensayos sobre autores, manuscritos, editores y lectores (2003), Edición y subversión. Literatura clandestina en el Antiguo Régimen (TurnerFCE, 2003), Elnegocio de la Ilustración. Historia editorial de la Encyclopédie, 1775-1800 (Libros sobre libros-FCE, 2006), entre otros.

Para quien no conozca el periplo intelectual de Darnton, baste decir que es uno de los especialistas en historia cultural del siglo XVIII francés más reconocido. Como si esto fuese poco, se ha especializado, simultáneamente, en una suerte de sub-disciplina histórica, algo así como "una historia dela edición y del libro", de la cual es pionero y en la que se ha consolidado como el más conocido especialista. A nadie sorprenderá, entonces, que Robert Darnton sea, en la actualidad, Director de la Biblioteca de la Univeridad de Harvard.

Sin recurrir a conocidos argumentos teóricos, defendidos por post-freudianos como Jung (que vinculan la estabilidad y recurrencia de algunas estructuras discursivas a su relación con arquetipos anclados en el inconsciente colectivo), nuestro autor desarrolló una idea altamente interesante que, para muchos, es uno de los puntos fuertes de su obra.

La idea de Darnton es que las "noticias" cotidianas de los medios, no son la crónica de acontecimientos radicalmente "nuevos". En las antípodas de la banal idea de recibo actual de que vivimos en "el vértigo de la noticia“, Darnton propone reivindicar "la permanencia" de ciertas narraciones, Más bien, las "noticias" o "novedades" que siempre trajo y trae la prensa no son sino re-emergencias de fragmentos literarios que ya fueron, previa y reiteradamente, historias cotidianas o relatos populares y que reaparecen recurrentemente en la historia. Para mostrar esta idea, Darnton analiza varios casos de "historias" que se reiteran cíclicamente en la historia cultural, al menos de Occidente, entre el siglo XVII y el XX³ .

2 Algunos títulos de importancia: Mesmerism and the End of the Enlightenment, Schoken Books, 1968; "In Search of the Enlightenment: Recent Attempts to Create a Social History of Ideas," The Journal of Modern History, Vol. 43, 1971; The Business of Enlightenment: A Publishing History of the Encyclopédie, 1775-1800. Cambridge, MA: Harvard Univ. Press, 1979; The Literary Underground of the Old Regime. Cambridge, MA: Harvard University Press, 1982; The Great Cat Massacre and Other Episodes in French Cultural History. New York: Basic Books, 1984. The Kiss of Lamourette: Reflections in Cultural History. New York, Norton, 1990; Edition et sédition. L’univers de la littérature clandestine au XVIIIe siècle, Paris: Gallimard, 1991; The Forbidden Best-Sellers of Prerevolutionary France, New York: Norton, 1996; The Corpus of Clandestine Literature in France, 1769-1789. New York, Norton,1995.

3 Darnton narra con pruebas contundentes, la reiteración "comunicacional" de una misma tragedia: "Una historia recurrente es el caso de los padres que en un extravío de la identidad asesinan a su propio hijo. Se publicó por primera vez en una rudimentaria hoja parisina de noticias en 1618. Luego cruzó por innumerables reencarnaciones: 
II.- Pero vayamos al libro que nos ocupa que, por cierto, tampoco resulta ser realmente novedoso. Por un lado, porque su edición inglesa data de 1982, pero, además, en buena medida está integrado por trabajos parciales, algunos de los cuales vieron la luz durante los años 70. La edición española llega tardíamente (en 2003), y su distribución en América Latina no ha sido, hasta donde sepamos, particularmente frondosa. Pero, quizás, la relevancia de este libro haya ido creciendo bastante después de su edición inglesa y ello por una serie de acontecimientos, políticos y culturales, querenovaron el interés de laacademia (y del público informado) por el pensamiento del siglo XVIII.

¿Nocabelahipótesis dequeestemosantealgoasícomoun "retornodelarazón" después dequeésta sufriere un desfiguramiento cierto durante dos períodos claves y casi sucesivos? Primero, desde los años 1930 (con el auge de los totalitarismos, iniciados entonces y todavía marginalmente vigentes) y, en segundo lugar, un nuevoy posterior cuestionamiento frontal, de 1968-70 en adelante, conlaeclosión de la llamada “postmodernidad". Quizás, la aparición de esta versión española de textos de la década de los años 70-80, tan tardíamente editada, tenga que ver con el surgimiento de un renovado interés por aquel período histórico, fuertemente racionalista, en el que nuestro autor se especializó. Quizás sea posible ensayar, a modo de elaboración provisoria, una doble tesis referida al "retorno de la razón" que estaría detrás del "revival" de los estudios sobre la Ilustración.

Desde fines delos 60s, la historia dela RevoluciónFrancesa (y forzosamente la del siglo que le precedió) sufrió una verdadera revisión gracias a los trabajos de François Furet y Mona Ozouf (Penser la Révolution, Dictionnaire critique de la Révolution française o Le Siècle de l'avènement républicain). Furet tuvo la visión de liberar la historia de la Revolución de lo que él llamó, la "vulgata marxista" (de la cual la obra de Soboul ${ }^{4}$ fue el ejemplo más elocuente). Con una visión menos grandilocuente, más genuinamente política y, sobretodo, más "laica", porque emancipada de la compulsiva "religión revolucionaria" que el marxismo había sembrado sembrado en la academia y en el mundo intelectual, Furet y Ozouf reconstruyeron la Revolución Francesa abusivamente transformada en una "avant-premiére" de octubre de 1917.

apareció en Toulouse en 1848, en Angôuleme en 1881, y finalmente en un periódico argelino moderno del que la rescató Albert Camus para reescribirla con un estilo existencialista para $L^{\prime}$ Étranger y Malentendu. Aunque los nombres, las fechas y los lugares varían, la forma del cuento es inequívocamente la misma en el curso de tres siglos". "El lector como misterio". Revista Fractal n 2, julio-septiembre, 1996, año 1, V.I, p. 77-98.

4 Secretario del'École des Annales, con Mathiez, Lefèbvre y Labrousse, Soboul construyó una Revolución tan jacobina y "marxistizada" que Robespierre terminó siendo el Arcángel Gabriel "anunciando" el futuro advenimiento de Vladimir Lenin. En nuestro país, Bentancourt Díaz, historiador, ensayista y filósofo comunista, de la Facultad de Humanidades, supo pergeñar en 1969 una lectura de "El Príncipe" tan leninista que estaba al borde de una falsificación. El procedimiento era recurrente en laépoca: véase Bresciano, Juan Andrés, "Elantifascimo ítalo-uruguayo en el contexto de la Segunda Guerra Mundial”, Revista DEP, No. 11, 2009 y su llamada 26, p. 102, sobre el texto de BentancourtDíaz,J:"Lapolítica exterior dela Revolución Francesa", Revista "Progreso", I.3, junio-septiembre 1940 y su reiterada tendencia a que "La propaganda de la asociación (se refiere a la asociación anti-fascista, el "Círcolo Italiano" y su revista "Progreso") suele incorporar referencias al pasado que permiten comprender procesos del más inmediato presente." El abuso del pasado para abonar dogmáticamente el presente y el uso del presente para reconstruir, de manera "partidaria", el pasado, era moneda corriente en los años anteriores a la Segunda Guerra Mundial, y lo sigue siendo en la actualidad. 
En ese sentido, los trabajos de Darnton se inscriben con naturalidad en esta interpretación irreverente del siglo XVIII que Furet y Ozouf, en buena medida, pusieron en marcha hace ya medio siglo. Aunque no podamos afirmar que Darnton se encuentre exactamente en esa línea, sí es convergente con trabajos actuales como La Ilustración Radical. La filosofía y la construcción de la Modernidad, 1650-1750, de Jonathan Israel o Los ultras de las Luces de Michel Onfray ${ }^{5}$, y otros intentos que, referidos a Darnton, apuntan a construir una relectura del siglo XVIII, de la Ilustración y de la Revolución que reúne los dos elementos novedosos arriba mencionados. Por un lado, liberar a esta nueva visión de aquella historia de las servidumbres dogmáticas mencionadas y, por el otro, recuperar la importancia de la operación racionalista (e incluso ultra-racionalista) que la Ilustración hubo de llevar a buen puerto, más allá de sus excesos más dogmáticos que, oportunamente, señaláramos en otros textos ${ }^{6}$.

Cabe preguntarse, pues, si no está operando una tendencia al redescubrimiento, revisión y reafirmación, de la Ilustración en el ámbito de la filosofía política. Esta tendencia quizás señale un cambio de orientación del pensamiento "posmoderno" que relanzó oportunamente un desafío a la soberbia, siempre algo demasiado resplandeciente, de la razón moderna. Aunque esta tendencia reivindicatoria no deja de coexistir con aquellos cuestionamientos que la posmodernidad intentó llevaradelante, podemos constatar que, al menos en terrenos de la Historia, es posible detectar un revival de los estudios sobre la Ilustración, así como un cuestionamiento de aquella lectura lineal del proceso intelectual que del siglo XVII, a través del XVIII, desemboca en la Revolución.

III.- Pero, recorridas estas hipótesis sobre las circunstancias que parecen haber "reactualizado" el interés por el pensamiento del siglo XVIII, ofrezcamos una idea aproximada de las virtudes y limitaciones del texto. Ello es importante porque este libro de Darnton es genuinamente original y no dejará de sorprender positivamente a más de un lector.

Darnton examina la finalización delAntiguo Régimen desde la perspectiva de la edición y publicación de la "literatura marginal"7 de las décadas previas a la Revolución por lo que, en buena medida, su texto es un estudio de "los vulgarizadores" de la Ilustración. Es decir de aquellos autores, totalo parcialmente desconocidos, que escribieron "a la sombra" de los nombres de la verdadera Ilustración que los precedió.

5 Onfray explicita su admiración por la obra de Darnton: "La cara oculta de las Luces. Para entrar en ese siglo, habría que citar todo el excelente trabajo de Robert Darnton, que ha revolucionado la manera de comprender esta época”. op. cit. p 307. Onfray reenvía, también, a varios textos de Darnton: Gens de Lettres, Odile Jacob, Paris, 1992, La Fin des Lumières. Le Mesmerisme et la Révolution, Paris. Perrin, 1995, para solo nombrar alguno de ellos.

6 Ver: Bonilla Saus, Javier, en coautoría con Arriola, Jonathan (2012) “Isaiah Berlin y la sombra de las Luces”. Cuadernos de CLAEH No. 100, Montevideo, Dic. 2012).

7 Darnton utiliza la expresión "Grub Street" para designar lo que llamamos "literatura marginal" o "panfletaria". "Grub Street" refiere a una calle de Londres donde, desde el siglo XVI al XIX trabajaron, con escaso éxito, autores de poca monta, poetas frustrados, literatos por encargo. En inglés, el término dejó de referir a una calle de la ciudad y su sentido se extendió a los sub-géneros "literarios" que allí se producían. 
Darnton utiliza una verdadera mina de documentos de época que encontrare, en Suiza, en los archivos de la Société typographique de Neuchâtel. En esta editorial, cercana a la frontera francesa, se imprimieron cientos y cientos de títulos censurados y perseguidos por la policía entre los años 1770 y 1800 . El negocio de esta Société era abastecer de libros a lectores franceses ávidos de la "literatura prohibida". La vastedad de esta fuente de documentos es comprobable en cada uno de los seis grandes capítulos que integran el libro.

Pero Darnton pretende “...llegar al fondo de la Ilustración” y“...examinarlo como se ha examinado la Revolución recientemente: desde abajo". Para entender ese "fondo de la Ilustración" transcribamos aquí el pedido de diciembre de 1772, del librero Chevrier, de Poitiers, al proveedor de Neuchâtel:

Esta es la lista de los libros filosóficos (sic) que quiero. Por favor envíe la factura por adelantado: Venus en el claustro o la monja en camisa, La Cristiandad al desnudo, Memorias de Mme. la marquesa de Pompadour, Estudio sobre el origen del despotismo oriental, El Sistema Natural, Teresa la filósofa, Margot la cantinera ${ }^{8}$.

Lo que se entiende por libros "filosóficos" en la carta no se corresponde con la visión canónica de los títulos que, teóricamente, desvelaban a los " $p h i$ losophes illustrés" de la historia oficial. Con la excepción de los dos títulos de Holbach", es evidente que la expresión libros "filosóficos" es, también, sinónimo de libros "transgresores" o "libertinos".

Una primera conclusión que surge de esta correspondencia es que, con toda seguridad, lo que Darnton llama con precisión "la baja literatura de la Ilustración tardía”, constituye un cuerpo de literatura a la vez muy diferente del que creasen los philosophes algunas décadas antes ${ }^{10}$.

Que esta "baja literatura" de la segunda mitad del siglo tuviese estas limitaciones no le quita real importancia histórica como deja claro Darnton en el último ensayo del libro: "Leer, escribir, publicar"11. No resulta difícil comprender que las obras de los verdaderos philosophes impactaron directamente en la concepción del mundo que sostenía al Antiguo Régimen y produjeron una suerte de "ruptura epistemológica" de la que éste nunca hubo de recuperarse.

8 Darnton, Robert, op. cit. p. 16.

9 "El Cristianismo al descubierto" y "El Sistema de la Naturaleza"

10 Darnton evita el concepto de "generación" y define dos "unidades demográficas" bien diferenciadas. La de los grandes philosophes nacidos entre 1689 y 1717, y la unidad demográfica siguiente, nacida en las dos primeras décadas del siglo, que no registra nombre alguno de envergadura: Suard, La Harpe, Marmontel, y ni el propio Beaumarchais más recordado por su mediocre perfil de literato que como filósofo, constituyeron herederos dignos de sus antecesores. Antoine de Rivarol en su "LePetit Almanach denosgrandshommes" de 1788 (Ver en BNF-Gallica http://gallica.bnf.fr/ark:/12148/bpt6k48117q Consulta del 04/06/14) describió con sorna, pero no sin exactitud, las limitaciones de esa plebe de auto-designados escritores y pseudo philosophes que poblaban las buhardillas de París. Si a veces es injusto (Restif de la Bretonne, Desmoulins o Fabre d'Eglantine, de alguna manera, "pasaron a la historia") en la mayoría de los casos las obras de esos autores desaparecieron porque eran libelos panfletarios, difamatorios o pornográficos.

11 Darton, Robert, op. cit., p 187-229. 
Quienes demolieron la Bastille, "le petit peuple de Paris", no habían leído la Encyclopédie. Darnton señala que, durante el siglo XVIII francés, hubo un aumento de la alfabetización ${ }^{12}$ pero, de ser cierto, eso no había multiplicado los lectores de d'Alembert o del Barón D'Holbach. Lo que se amplió fueron los lectores de "baja literatura". Por lo que los "...escritorzuelos hambrientos..." fueron decisivos en la movilización de Paris y de sus "faubourgs". Sus obras (muchas pobremente editadas en Neuchâtel) cumplieron la función de los volantes, panfletos, editoriales, artículos de prensa, emisiones televisivas o las hoy llamadas "redes sociales" que, en procesos revolucionarios contemporáneos, hubieron de ser decisivos. La movilización del odio del "petitpeuple" contra la Monarquía y Luis XVI, y la movilización subsecuente, le deben más a Brissot, a Le Senne o a Mauvelain que a los "verdaderos" philosophes.

Quizás lo que Darnton no destaca con suficiente énfasis es que la eficacia política de esta "baja literatura", y su impacto altamente subversivo, solo tuvo lugar porque la Ilustración temprana y los philosophes habían arrasado con toda legitimidad y respeto intelectual y ético para con la Monarquía, la Iglesia $\mathrm{y}$, todo el Antiguo Régimen ${ }^{13}$. Cincuenta años más tarde, estaba abierta la posibilidad para que algunos de estos escritorzuelos de "bas étage" se ocupasen de los supuestos vicios sexuales de la Reina.

III.- A modo de reflexión final, este libro debe ser leído, sobretodo, como una "muestra" de una amplio proceso de relectura del siglo XVIII y de la Revolución Francesa que tiene ya unas cuantas décadas de comenzado. El enfoque de Darnton, en sus seis capítulos relativamente autónomos pero temáticamente bien relacionados, tiene la virtud de mostrarnos aspectos poco conocidos de un momento clave de la evolución de las ideas políticas y sociales en Francia durante el siglo XVIII. Pero la principal virtud de este trabajo es que parece haber logrado despojarse de toda tonalidad épica y los relatos que lo integran muestran los más cotidianos, íntimos, y mezquinos detalles humanos que, en una muy amplia medida, hacen también parte fundamental de la trama de la historia.

12 Esun estudio clásico de Louis Maggiolo, Darnton estima en 9.6 millones los franceses capaces de escribir su nombre en 1780, para un total de 26 millones. Los datos se basan en el trabajo de Fleury, Michel y Valmary, Pierre: "Les progrès de l'instruction élémentaire de Louis XIV à Napoléon III d'après l'enqûete de Louis Maggiolo (18771879)", Population, 1957, p. 71-92, Paris.

13 "La policía se tomaba los libelos en serio porque su efecto sobre la opinión pública también era serio, y la opinión pública cobró un poder notable en los años de decadencia del Antiguo Régimen”, Darnton, p. 223. 